\title{
A proposal of topographic map symbols for large-scale maps of urban areas in Brazil
}

\author{
Claudia Robbi Sluter ${ }^{\mathrm{a},}$, Silvana Philippi Camboim ${ }^{\mathrm{b}}$, Andrea Lopes Iescheck ${ }^{\mathrm{a}}$, Luciane Borges \\ Pereira $^{\mathrm{c}}$ \\ ${ }^{a}$ Department of Geodesy, Federal University of Rio Grande do Sul, Av. Bento Gonçalves, 9500, CEP 91540-000, Porto Alegre, \\ Brazil,robbi.sluter@ufrgs.br, andrea.iescheck@ufrgs.br, \\ ${ }^{b}$ Department of Geomatics, Federal University of Parana, Centro Politénico, Jardim das Américas, Caixa Postal 19001, CEP \\ 81531-980 Curitiba, Brazil, silvanacamboim@ufpr.br \\ ${ }^{c}$ Department of Geoprocessing and Estate Management, COPEL Geração e Transmissão S/A, José Isidoro Biazetto Street, 158, CEP \\ 81200-240, Curitiba, Brazil, luciane.pereira@copel.com \\ * Corresponding author
}

Keywords: Topographic mapping; map symbology; topographic mapping standardization.

This paper addresses a historical issue in Brazil that is that topographic mapping has been performed without application of the theories of cartography to local reality. With the lack of research on this subject, the rules and standards for topographic mapping in Brazil are based on solutions that have been developed in other countries. Even though topographic maps are not a frequent topic of cartographic research, as cited by Kent (2009), when the methods, techniques, and standards are imported from other countries, they are established by considering different natural, rural, and urban landscapes; different histories of land use and occupation; and different cultures. Consequently, it is essential to develop studies that address the theoretical issues of topographic mapping and to verify their suitability to Brazilian reality, considering the geographical aspects that must be represented in topographic mapping. Such a foundation of scientific knowledge is essential to producing solutions that are adapted to the environmental conditions and needs of Brazilian users and society.

This problem is even more pronounced regarding large-scale mapping, which is necessary for the management of urban settlements. The migration from computer-aided design (CAD) to geographic information system (GIS) environments in map production led to the need for proposing better solutions to define the symbology to be used as well as the digital storage of the maps. Considering this, in 2007, the Câmara Técnica de Cartografia e Geoprocessamento CTCG of Paraná State, Brazil, formed a working group to improve the technical recommendations for topographic mapping. In those recommendations, the symbology for topographic mapping at large scales for the municipalities of Paraná State was not standardized with cartographic principles (Bertin, 1983; Keates, 1973; MacEachren, 1994; MacEachren, 1995). Therefore, it did not establish a classification for the elements to be mapped and, consequently, did not follow methodological and systematic reasoning. Some of the developments obtained by that working group since 2007 are available in Comé (2014), Comé and Sluter (2015), Natingue (2014) and Araujo et al. (2017).

Due to this motivation, we describe the method and related results that we have developed to propose a set of symbols for topographic mapping at large scales for the municipalities of Paraná, Brazil. The steps and the sequence of tasks in our method are similar to those of Ory et al. (2013), who proposed a systematic approach to formalizing and identifying topographic styles of different countries. Whereas Ory et al. (2013) searched for an understanding of topographic styles by comparing sets of elements and their semantics and symbols designed for the topographic mapping of France and Switzerland, our goal is to define a topographic style for large-scale urban maps in Brazil. Then, we developed the study by considering cartographic principles and aligning them with the definitions of Brazilian systematic mapping. For that reason, the first step in the research was making decisions about which elements should be part of the 1:2,000 scale topographic mapping. As one result of the study, we decided that the mapping should represent 152 elements that we grouped into ten categories. We have also defined the meaning of each element. The element meanings were the basis for establishing classes and subclasses. Next, a symbology was proposed, including the representation of toponyms.

To describe how we created the symbols, we exemplify the streets and cycle path elements in this short paper. In a 1:2,000 scale map, the graphics primitive for the street element is an area, and for the curb of the sidewalk, it is a line. The level of measurement for classes established by the existence of pavement is nominal, and we chose the color hue as the visual variable. Because we designed topographic maps, we decided that we should select color hues by the color association criterion. Thus, we depicted paved streets in a grey hue that reminds the map user of asphaltic pavement, and for unpaved streets, we chose a brown hue that reminds the user of bare ground color. The decision to use a brown color hue for the color association with the bare ground is similar to depicting brown contour lines to represent relief (Keates, 1973). For the representation of the existence of a curb at sidewalks, the level of measurement is ordinal. We established a visual variation in the line symbol as continuous and dashed lines. The cycle path class is different from 
the street class at the nominal level of measurement. Therefore, we defined the difference between classes using different color hues. One complexity related to the design of the symbols is the need to depict in the urban topographic maps several different elements that must be individualized because they are essential spatial references, such as bank branches, museums, and theatres. However, it is well-known that the limitations of our visual perception do not allow us to distinguish several different colors or even point symbol shapes. Consequently, we had to define that representations of some element classes should be accomplished by including their names, such as the name of each school.

We evaluated the quality of the research results using two criteria: visibility and legibility (Keates, 1973; Keates, 1989). The old symbol standardization is not visually efficient because it is difficult for map users to detect and discriminate between represented elements, even when the map users use the map legend. For instance, the symbols for buildings make it difficult to recognize the different patterns of urban occupation, as well as the spatial relations between the buildings and streets and other urban properties of the town. The users can see each symbol, but it is difficult for them to discriminate between different elements such as buildings and property or street limits. Figure 1(a) illustrates a part of Cascavel city represented with the old symbols and, Figure 1(b) shows the same part of Cascavel city depicted with the symbology proposed by us.
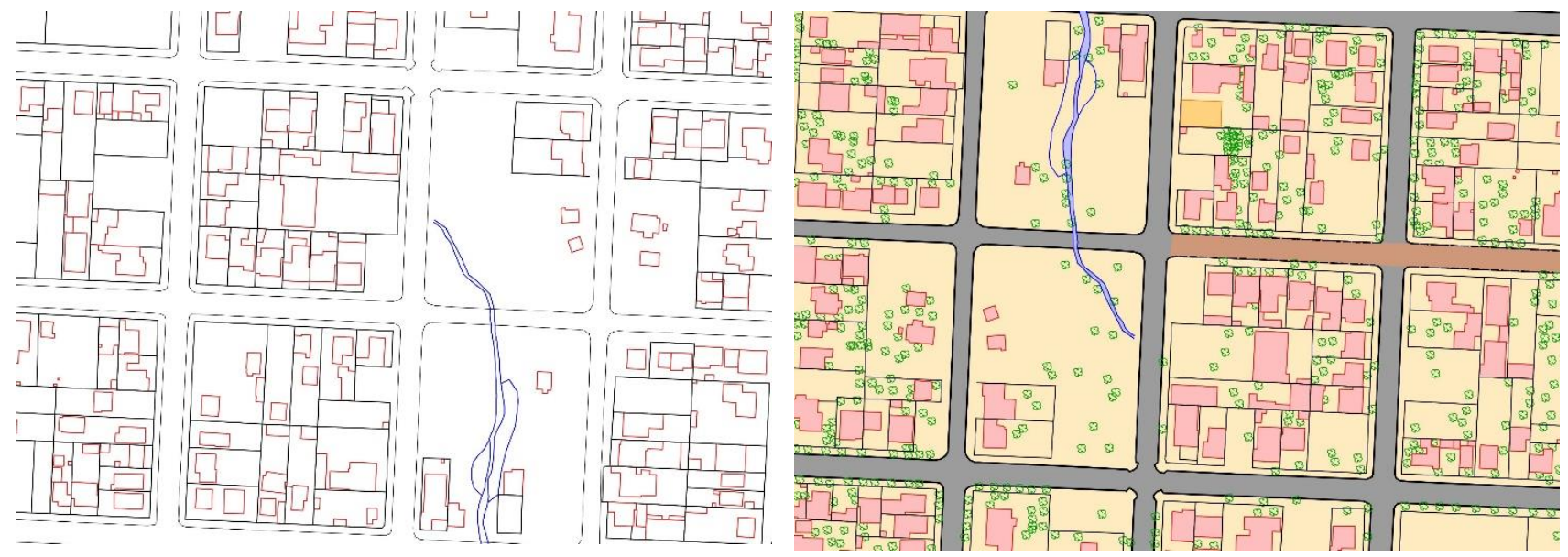

Figure 1. (a) Picture of a part of Cascavel topographic map with the old symbols and (b) with the newly proposed symbols.

We achieved results that are essential for the series of research products we develop in our laboratory and proposing a scientific framework for topographic mapping that benefits a large group of producers and users of urban maps in Brazil. The differences between thematic and topographic mapping helped us to show CTCG members that topographic mapping should be accurately representative of the urban landscape to support thematic mapping and spatial analysis. That understanding made it possible to establish the set of elements and their meanings that should be part of 1:2,000 scale topographic maps. Defining classification criteria allowed us to determine in which topographic mapping category we should include each element. Designing some areas' elements with area instead of a line graphic primitive made the maps' representations visually better and less complex. A less complex visual image makes it easier for users, even the non-specialists, to identify each map element, distinguish it from the other elements, and understand its meaning. In the end, we verified the efficiency of the proposed set of symbols with two criteria: visibility and legibility. This paper has been accepted for publication in the Cartographic Journal. Thus, we request that it is not published in the ICC 2019 Annals in the case it is accepted for presentation.

Comé, S. and Sluter, C.R. (2015) "Uma Proposição para Detecção das Condições Geométricas em Cartas Topográficas de Regiões Urbanas na Escala 1:10,000 Derivadas de 1:2,000” Revista Brasileira de Cartografia 67 (6) pp.1091-1102. Comissão Nacional de Cartografia (CONCAR) (2018) "Panorama Histórico" Available at: http://www.concar.gov.br/panoramaHist.aspx (Accessed: 18th March 2018).

Kent, A.J. (2009) "Topographic Maps: Methodological Approaches for Analyzing Cartographic Style” Journal of Map \& Geography Libraries 5 (2) pp.131-156 DOI:10.1080/15420350903001187.

Natingue, G. (2014) "Proposta de Simbologia para as Cartas na Escala 1:5,000 no Contexto de Mapeamento Topográfico do Estado do Paraná" (M.Sc. thesis) Federal University of Paraná Available at: https://acervodigital.ufpr.br/handle/1884/40870 (Accessed: 2nd April 2016).

Ory, J., Christophe, S. and Fabrikant, S.I. (2013) "Identification of Styles in Topographic Maps" 26th International Cartographic Conference Dresden, Germany: 25th-30th August International Cartographic Association, pp.1-11 Available at: https://icaci.org/files/documents/ICC_proceedings/ICC2013/_extendedAbstract/274_proceeding.pdf (Accessed: 2nd April 2016). 